\title{
Time Until Loss to Follow-Up, Incidence, and Predictors Among Adults Taking ART at Public Hospitals in Southern Ethiopia
}

This article was published in the following Dove Press journal: HIVIAIDS - Research and Palliative Care

\author{
Samuel Dessu (1D' \\ Molalegn Mesele (D) ${ }^{2}$ \\ Aklilu Habte $\mathbb{D}^{3}$ \\ Zinabu Dawit ${ }^{4}$
}

'Department of Public Health, College of Medicine and Health Sciences, Wolkite University, Wolkite, Southern Ethiopia, Ethiopia; ${ }^{2}$ Department of Midwifery, College of Medicine and Health Sciences, Wolaita Soddo University, Wolaita, Southern Ethiopia, Ethiopia; ${ }^{3}$ Department of Public Health, College of Medicine and Health Sciences, Wachamo University, Hossana, Southern Ethiopia, Ethiopia; ${ }^{4}$ Department of Nursing, Arba Minch Health Science College, Arba Minch, Southern Ethiopia, Ethiopia
Correspondence: Samuel Dessu Department of Public Health, College of Medicine and Health Sciences, Wolkite University, Wolkite, Southern Ethiopia, Ethiopia

Tel +25 I 910883594

Email dessusamuel@yahoo.com
Introduction: According to the World Health Organization, more than seventeen million people were accessing ART in 2015 globally. Adherence to effective ART reduced the risk of transmitting the virus to uninfected persons. The government and other stakeholders' focus was high to reduce the rate of loss to follow-up in HIV programs among patients who are already on ART follow-up, but its incidence rate increases from time to time.

Methods: A retrospective cohort study was conducted among the records enrolled from 1 January 2013 to 30 December 2017 at Public hospitals in Southern Ethiopia. Data were entered into Epi info V 7 and exported to STATA V 14 for analysis. The KaplanMeier survival curve together with a log rank test was used to estimate the survival time of the ART attending patients. Variables which had p-value $<0.05$ in multivariable analysis using the cox proportional hazard model were declared as statistically significant.

Results: The incidence rate of loss to follow-up from ART services among adults attending ART was $6.48(95 \%$ CI:5.67,7.29) per 1000 person months. The cumulative survival probability at the end of the 10th, 20th, 40th and 60th follow-up month was 0.89 (95\% CI:0.87,0.91), $0.82 \quad$ (95\% CI:0.79,0.85), $0.78 \quad(95 \% \quad \mathrm{CI}: 0.75,0.81)$ and 0.74 (95\% CI:0.70,0.77), respectively. Distance $>5$ kilometers (AHR:3.71; 95\% CI:2.32,5.95), not having registered phone number (AHR:2.52; 95\% CI:1.76,3.60), not initiating Isoniazid (AHR:2.15; 95\% CI:1.50,3.08), body mass index $<18.50 \mathrm{~kg} / \mathrm{m}^{2}$ (AHR:1.87; 95\% CI: 1.18; 2.97 ) and not having primary caregiver (AHR: 2.59 ; 95\% CI: $1.84,3.66$ ) were statistically significant predictors of loss to follow-up.

Conclusion: The time until loss to follow-up was high in the first 20 months of the initiation of the ART and it declines after 20 months; longer distance between home and hospital, not having registered phone number, not initiating INH, lower body mass index and not having primary caregiver were the independent predictors of loss to follow-up from ART services.

Keywords: loss to follow-up, incidence, survival time, predictor, ART

\section{Introduction}

Despite the gradual decline in new adult HIV infections from an estimated 13,394 for the year 2016 to 11,613 in 2019 in Ethiopia, ${ }^{1}$ antiretroviral therapy (ART) increases the life expectancy of HIV (human immunodeficiency virus) infected individuals through reducing the mortality rate secondary to HIV, but patients' continuous and regular follow-up is mandatory. ${ }^{2}$ According to the World Health Organization (WHO), more than seventeen million people were accessing ART in 2015 globally. $^{3}$ 
Effective ART can control the HIV virus and prevent transmission. A study conducted in 2011 revealed that adhering to effective ART minimizes the hazard of transmitting HIV to HIV free sexual partners by $96 \%{ }^{4}$ According to the World Health Organization (WHO) 2018 and UNAIDS 2019 global HIV/AIDS epidemic report, ART had a significant contribution to the fall in new HIV infections by $37 \%$ and HIV/AIDS-related deathes by $45 \%$ correspondingly. ${ }^{5,6}$

Loss to follow-up (LTFU) from ART services is defined as a patient who had no contact for three consecutive months or longer after the last appointment for antiretroviral (ARV) refills. ${ }^{7}$ The government and other stakeholders' focus was high to reduce the rate of loss to follow-up in HIV programs among patients who are already on ART follow-up, but its incidence density rate ranges from 8.80 to 26.60 per person months. ${ }^{8-10}$

Different studies showed that there was a high magnitude of LTFU among patients living with HIV. For example, in sub-Saharan Africa LTFU is an estimated 20$40 \%,{ }^{11}$ in low-income countries the risk of LTFU was found to be $4.1 \%$ in Asia, and $21.8 \%$ in western Africa. ${ }^{12}$ Besides, the cumulative incidence of LTFU in Ethiopia was $7.7 \%, 11.8 \%$, and $16.6 \%$ at 6,12 , and 24 months, respectively. ${ }^{13}$

Loss to follow-up from ART services has been recognized as an obstacle for attainment of the second 90 in the Joint United Nations Programme on HIV and AIDS (UNAIDS) 90-90-90 treatment targets as it affects the sustainable intake of the treatment. Furthermore, loss to follow-up affects the performance of the third 90 of the UNAIDS 90-90-90 target that aims to achieve $90 \%$ of virally suppressed patients on ART. This is due to the fact that an interruption to ART follow-ups lowers the success of the treatment and consequently leads to a decrease in the number of CD4 cells and increases the number of viral counts. ${ }^{14}$

Among programs in HIV/AIDS, loss to follow-up and mortality are the continuous and dynamic challenges to the upgrading of HIV treatment and care. ${ }^{7}$ Loss to follow-up from ART service resulted in severe morbidities and mortality related to the immunological deficiencies (AIDS) due to the HIV virus. ${ }^{12}$ In addition, it increases AIDS related hospitalizations, morbidity and death in resource limited countries and it is considered as an everyday threat. ${ }^{16,17}$

Certain studies indicated that loss to follow-up is related with certain factors such as age, sex and distance between home and hospital ${ }^{7}$ among socio-demographic characteristics and WHO clinical staging, ${ }^{15,18}$ opportunistic infections (OIs), ${ }^{19} \mathrm{CD} 4$ cell count, ${ }^{8,20,21}$ functional status, ${ }^{18-20}$ initiation of prophylaxis and availability of care givers among clinical and related characteristics. In Ethiopia, information related to loss to follow-up from ART services and factors associated with it is too low. Therefore, this study aims to determine the time until loss to follow-up, incidence and its predictors among patients attending ART at public hospitals in Southern Ethiopia.

\section{Methods}

\section{Study Design and Setting}

Facility-based retrospective cohort longitudinal study was conducted at public hospitals in Southern Ethiopia. Jinka General Hospital, Arba Minch General Hospital, Ottona Teaching and referral Hospital, Chencha district Hospital and Sawla General Hospital were randomly selected using the lottery method. The study was conducted from 1 to 30 March 2018. These hospitals, Jinka District Hospital, Arba Minch General Hospital, Ottona teaching referral Hospital and Sawla General Hospital were located $563 \mathrm{~km}, 505 \mathrm{~km}$, $378 \mathrm{~km}$ and $514 \mathrm{~km}$ away from Addis Ababa, the capital city of Ethiopia, respectively. All these hospitals provide HIV/AIDS interventions, including free diagnosis, treatment and monitoring. Within this study period, there were a total of 1695 ART attending patients in the hospitals.

\section{Study Populations}

All records of adults enrolled on ART at public hospitals in Southern Ethiopia from 1 January 2013 to 30 December 2017 were the source populations and all selected records from source populations were study populations. It was an open cohort study and anyone can enter into the cohort and exit from the cohort within the time frame. All records of adults enrolled on ART at public hospitals in Southern Ethiopia from 1 January 2013 to 30 December 2017 were included and records which did not mention the ART initiation time, the outcome and recorded death were excluded from the study. The end point of this study was either loss to follow-up, transferred to another institution or follow-up time was completed when the patient retained on treatment.

\section{Sample Size Determination and Procedures}

Sample size was calculated using the open epi statistical software based on the assumption: 95\% CI, Power: 80, 
Ratio of exposed to non-exposed ratio: 1, proportion of unexposed with outcome: 19, AHR: $1.61 .^{15}$ Therefore, the predetermined sample size was 836 . In adding $10 \%$ for incomplete records, the total sample size for the study was 920. Sample size was allocated to each hospital proportionally based on the number of adult ART attending patients. Simple random sampling technique was used to recruit predetermined sample size by using the registration/card number of the clients enrolled. Computer generated random numbers were used to select the records of the study participant within each consecutive year.

\section{Study Variables}

The dependent variable was time until loss to follow-up from ART services and the independent variables were age, sex, marital status, educational status, religious status, residence, occupational status, habit of alcohol intake, habit of cigarette smoking, distance between home and hospital, registered phone number, WHO clinical stage, functional status, most recent CD4 cell count, most recent viral load, occurrence of opportunistic infections (OIs), disclosure status, active tuberculosis (TB), length of follow-up, partner HIV status, Isoniazid (INH) initiation, Cotrimoxazole preventive therapy (CPT) initiation, body mass index (BMI), availability of primary care giver and adherence on ART.

\section{Data Collection Tool and Procedures}

The data extraction tools were prepared in English which include socio-demographic characteristics and clinical related information. The data was collected by ten researchers and supervised by five researchers who were trained on comprehensive HIV care to ensure the quality of data. For data collection, patient's medical records and ART electronic databases were used.

\section{Data Quality Assurance}

Data quality was assured by caring out careful design of data extraction formats and by giving adequate training and follow-up for data collectors and supervisors. Intensive supervision was done by supervisors during the whole period of data collection. The investigators also made random cross checks for their completeness, accuracy, and consistency at the end of each day and corrective measures were undertaken with all the research team members. Sensitivity analysis was conducted, which was $79 \%$.

\section{Data Processing and Analysis}

After checking the data for completeness and consistency, it was entered into EPI info version 7 and then exported to STATA version 14 for cleaning, coding and analysis. Descriptive statistics were carried out and summarized using tables and graphs. Incidence density rate was determined by using person time of follow-up as a denominator for the entire cohort and for groups classified based on socio-demographic and clinical characteristics. KaplanMeier survival curve was used for analysis of probabilities of loss to follow-up. Log rank test was used to compare survival curves between the different categories of the explanatory variables.

Both bivariate and multivariable Cox proportional hazard models were used to identify the predictors of time until loss to follow-up from ART services among adults on ART. CHR, AHR and 95\% CI were calculated using Cox proportional hazard model. Variables which had a p-value less than 0.05 in the multivariable Cox proportional hazard model were considered statistically significant predictors of loss to follow-up.

\section{Ethical Consideration}

Ethical clearance was obtained from Arba Minch University, College of Medicine and Health Sciences ethical review board. In addition, permission letters were obtained from the Arba Minch University and South Nations Nationalities and People's Regional State (SNNPR) health bureau and the corresponding hospitals. Appropriate measures were applied to ensure the confidentiality of the data. In addition, this study was conducted in accordance with the Declaration of Helsinki.

\section{Results}

In this study a total of 920 patient records were reviewed, with a response rate of $100 \%$. The minimum and maximum age of the respondents was 18 and 62 years with the mean of $31.75( \pm 9.91)$ years. Majority of the respondents $(53.70 \%)$ were in the less than 30 years old age category and nearly one fourth $(24.90 \%)$ were categorized under the age category 31-39 years old; but among the lost from ART follow-up, nearly one fifth $(19.30 \%)$ and one fourth (25.50\%) were under the age category of 31-39 and 40 years and above, respectively. Among the reviewed records, $362(39.35 \%)$ were males and among the lost, nearly half $(50.50 \%)$ were males. Regarding the marital status of the respondents, $150(6.30 \%)$ were single and the 
remaining $615(66.80 \%), 80(8.70 \%)$ and $75(8.20 \%)$ were married, divorced and widowed, respectively; among the lost from the care, more than half $(54.20 \%)$ were married.

Among the reviewed records, 146 (15.90\%) had no formal education while the least $(13.80 \%)$ studied college and above. Among ART patients who were lost from the care, the majority of them $(36.50 \%)$ studied secondary studies. In considering religious status of the respondents, 349 (37.90\%), $95(10.30 \%)$ and 430 (46.70\%) were Orthodox, Muslim and Protestants, respectively, while among the lost from the care, nearly half (47.90\%) were Orthodox religion followers. Three hundred twenty seven $(35.50 \%)$ of the respondents were rural residents and among the lost from ART service, 119 (62.00\%) of them were rural residents.

Around one fifth $(20.80 \%)$ of the respondents were government employees while housewives, daily laborers, private employees and merchants accounted for 275 (29.90\%), 117 (12.70\%), 87 (9.50\%) and $121(13.20 \%)$, respectively. Nearly one fifth $(18.80 \%)$ of the lost from follow-up were government employees. Among ART care attendants, $380(41.30 \%)$ had more than five kilometers between their home and the health facility and from them, $159(82.80 \%)$ were lost from the service. Nearly one tenth $(10.40 \%)$ of the respondents had a habit of alcohol intake and $24(2.60 \%)$ of the respondents had a habit of cigarette smoking. Among the respondents lost from follow-up, 51 $(26.60 \%)$ and $18(9.40 \%)$ had a habit of alcohol intake and cigarette smoking, respectively (Table 1).

\section{Clinical and Related Characteristics}

Nearly one fourth $(23.50 \%)$ of the respondents were categorized under WHO clinical stage I while 436 (47.40\%) and $268(29.10 \%)$ were categorized under WHO clinical stage II and III, respectively. In addition, among the lost from ART services, $44(22.90 \%), 66(34.40 \%)$ and 82 $(42.70 \%)$ of the patients were categorized under WHO clinical stage I, II and III, respectively. In considering functional status, more than three fourths $(78.90 \%)$ of the respondents were working, $136(14.80 \%)$ were ambulatory

Table I Socio-Demographic Characteristics of ART Attending Patients at Public Health Facilities of Southern Ethiopia, 2018

\begin{tabular}{|c|c|c|c|}
\hline \multirow[t]{2}{*}{ Variables } & \multirow[t]{2}{*}{ Categories } & \multicolumn{2}{|c|}{ Status } \\
\hline & & Loss to Follow-Up & Censored \\
\hline \multirow[t]{2}{*}{ Sex } & Male & 97 (50.50\%) & $265(36.40 \%)$ \\
\hline & Female & $95(49.50 \%)$ & $463(63.60 \%)$ \\
\hline \multirow[t]{4}{*}{ Marital status } & Single & 65 (33.90\%) & 85 (II.70\%) \\
\hline & Married & 104 (54.20\%) & $5 \mathrm{II}(70.20 \%)$ \\
\hline & Divorce & $7(3.60 \%)$ & $73(10.00 \%)$ \\
\hline & Widowed & $16(8.30 \%)$ & $59(8.10 \%)$ \\
\hline \multirow[t]{4}{*}{ Educational status } & No formal education & $29(15.10 \%)$ & $117(16.10 \%)$ \\
\hline & Primary (I-8) & $64(33.30 \%)$ & $294(40.40 \%)$ \\
\hline & Secondary (9-12) & $70(36.50 \%)$ & $219(30.10 \%)$ \\
\hline & College and above & $29(15.10 \%)$ & $98(13.50 \%)$ \\
\hline \multirow[t]{4}{*}{ Religious status } & Orthodox & $92(47.90 \%)$ & 257 (35.30\%) \\
\hline & Muslim & $13(6.80 \%)$ & $82(11.30 \%)$ \\
\hline & Protestant & $82(42.70 \%)$ & $348(47.80 \%)$ \\
\hline & Others & $5(2.60 \%)$ & $4 \mathrm{l}(5.60 \%)$ \\
\hline \multirow[t]{6}{*}{ Occupational status } & Government employee & $36(18.80 \%)$ & $155(21.30 \%)$ \\
\hline & House wife & $29(15.10 \%)$ & $246(33.80 \%)$ \\
\hline & Daily laborer & $31(16.10 \%)$ & $86(11.80 \%)$ \\
\hline & Private employee & 45 (23.40\%) & $42(5.80 \%)$ \\
\hline & Merchant & $28(14.60 \%)$ & $93(12.80 \%)$ \\
\hline & Others & $23(12.00 \%)$ & $106(14.60 \%)$ \\
\hline \multirow[t]{2}{*}{ Registered phone number } & Yes & $63(32.80 \%)$ & $623(85.60 \%)$ \\
\hline & No & $129(67.20 \%)$ & 105 (I4.40\%) \\
\hline
\end{tabular}


and $58(6.30 \%)$ were bed ridden. More than one thirds $(35.30 \%)$ of the respondents had a most recent CD4 count less than 200, among them, $74(38.50 \%)$ were lost from ART treatment.

In considering recent viral load of the participants, 727 (79.00\%), $51(5.50 \%)$ and $46(5.00 \%)$ had less than 200 , 200-1000 and more than 1000 and the remaining 96 $(10.40 \%)$ of the participants did not have registered viral load. Among the losses from ART services, more than two thirds $(68.20 \%)$ had less than 200 viral load while 15 $(7.80 \%)$ and $25(13.00 \%)$ had $200-1000$ and more than 1000 , respectively. The remaining $10.90 \%$ from the loss did not have recorded viral load.

Among the respondents, $145(15.80 \%)$ had faced at least one recorded opportunistic infections and of them, $63(32.80 \%)$ were lost from ART services. Specific to the total durations under ART, one fourth $(25.50 \%)$ attended for a duration of 12-23 months while the remaining 146 $(15.90 \%)$ and $539(58.60 \%)$ attended for less than 12 months and for more than 24 months, respectively. Most of the respondents (55.70\%) lost from ART were before 12 months of initiation of follow-up. Around two thirds $(63.50 \%)$ of the respondents initiated INH prophylaxis and among them, $56(29.20 \%)$ were lost from follow-up.

Specific to this study, $171(18.60 \%)$ of the respondents had BMI less than $18.5 \mathrm{~kg} / \mathrm{m}^{2}$ while $647(70.30 \%)$ had between $18-24.9 \mathrm{~kg} / \mathrm{m}^{2}$ and the remaining $11.10 \%$ had more than $25 \mathrm{~kg} / \mathrm{m}^{2}$. Most of the lost from ART service $(45.80 \%)$ had BMI between 18 and $24.9 \mathrm{~kg} / \mathrm{m}^{2}$. In considering the ART initiation period, most $(32.40 \%)$ were initiated in 2013 while 192 (20.90\%), 177 $(19.20 \%), \quad 151 \quad(16.40 \%)$ and $102(11.10 \%)$ were initiated in 2014, 2015, 2016 and 2017, respectively. More than three fourths $(85.90 \%)$ of the participants had a primary care giver and among them, $56.30 \%$ were lost from ART services.

In this study, nearly two thirds of the respondents disclosed themselves, among them, 467 (63.50\%) of them were lost from ART services. Regarding partners' HIV status, $134(14.60 \%)$ of the respondent's partners were HIV positive, among them, $34(17.70 \%)$ were lost from ART service. More than half $(51.20 \%)$ of the respondents developed active $\mathrm{TB}$ and more than half (52.10\%) of those who developed active TB were lost from ART service. In considering the initiation of CPT, $774(84.10 \%)$ of the ART attending patients initiated CPT and of them who initiated CPT, $159(82.80 \%)$ were lost to follow-up from ART services. More than two thirds $(68.40 \%)$ of the respondents adherence to ART was good and more than one fourth $(27.10 \%)$ of those who were fair/poor in adherence were lost from ART services (Table 2).

Table 2 Clinical Characteristics of ART Attending Patients at Public Hospitals in Southern Ethiopia, 2018

\begin{tabular}{|c|c|c|c|}
\hline \multirow[t]{2}{*}{ Variables } & \multirow[t]{2}{*}{ Category } & \multicolumn{2}{|c|}{ Status } \\
\hline & & Loss to Follow-Up & Censored \\
\hline \multirow[t]{3}{*}{ Functional status } & Working & II 4 (59.40\%) & 612 (84.10\%) \\
\hline & Ambulatory & $58(30.20 \%)$ & $78(10.70 \%)$ \\
\hline & Bed ridden & $20(10.40 \%)$ & $38(5.20 \%)$ \\
\hline \multirow[t]{3}{*}{ Most recent CD4 cell count } & Less than 200 & 74 (38.50\%) & $25 \mathrm{I}(34.50 \%)$ \\
\hline & $200-500$ & $88(45.80 \%)$ & 289 (39.70\%) \\
\hline & More than 500 & $30(15.60 \%)$ & I 88 (25.80\%) \\
\hline \multirow[t]{3}{*}{ Duration of stay under ART (in month) } & Less than 12 & 107 (55.70\%) & 39 (5.40\%) \\
\hline & $12-23$ & $70(36.50 \%)$ & 165 (22.70\%) \\
\hline & $\geq 24$ & I5 (7.80\%) & 524 (72.00\%) \\
\hline \multirow[t]{3}{*}{ Body mass index $\left(\mathrm{kg} / \mathrm{m}^{2}\right)$} & Less than 18.5 & 75 (39.10\%) & $96(13.20 \%)$ \\
\hline & $18-24.9$ & $88(45.80 \%)$ & $559(76.80 \%)$ \\
\hline & $\geq 25$ & $29(15.10 \%)$ & $73(10.00 \%)$ \\
\hline \multirow[t]{5}{*}{ ART initiation year } & 2013 & 45 (23.40\%) & $253(34.80 \%)$ \\
\hline & 2014 & $40(20.80 \%)$ & $152(20.90 \%)$ \\
\hline & 2015 & 35 (I8.20\%) & 142 (19.50\%) \\
\hline & 2016 & $42(21.90 \%)$ & $109(15.00 \%)$ \\
\hline & 2017 & 30 (15.60\%) & 72 (9.90\%) \\
\hline
\end{tabular}




\section{Incidence of Loss to Follow-Up}

The study participants were followed for a total of 29,623 months with a median of 33 months (IQR: 16-49). Among the respondents, a total of $192 \mathrm{HIV}$ infected patients were lost to follow-up from ART services. Among them, 125 (65.10\%) were lost to follow-up within the first 12 months of the initiation of the treatment. Nearly one fifth of the lost from ART (19.26\%) and 18 (9.38\%) were lost at the second 12 months and third 12 months of the initiation of ART followup, respectively. The remaining were lost at the fourth and the last 12 months, both time frames accounted for 3.13\% equally. Therefore, the incidence density rate of loss to follow-up from ART services among ART attending patients was 6.48 (95\% CI: 5.67, 7.29) per 1000 person months.

\section{Time until Loss to Follow-Up Among ART Attending Patients}

In this study, the minimum and the maximum follow-up period was two months and sixty months, respectively. The cumulative survival probability at the end of the 10th month was 0.89 (95\% CI: $0.87,0.91)$ while it was $0.82(95 \%$ CI: $0.79,0.85)$ and $0.80(95 \%$ CI: $0.77,0.83)$ at the 20th and 30th follow-up month, respectively. In addition, the cumulative survival probability at the 40th, 50th and 60th follow-up month was 0.78 (95\% CI: $0.75,0.81)$, 0.77 (95\% CI: 0.74, 0.79) and 0.74 (95\% CI: 0.70, 0.77), respectively (Figure 1).

\section{Log Rank Estimate of the Variables}

In determining the log rank estimate of the loss to followup among variables, both socio demographic and clinical

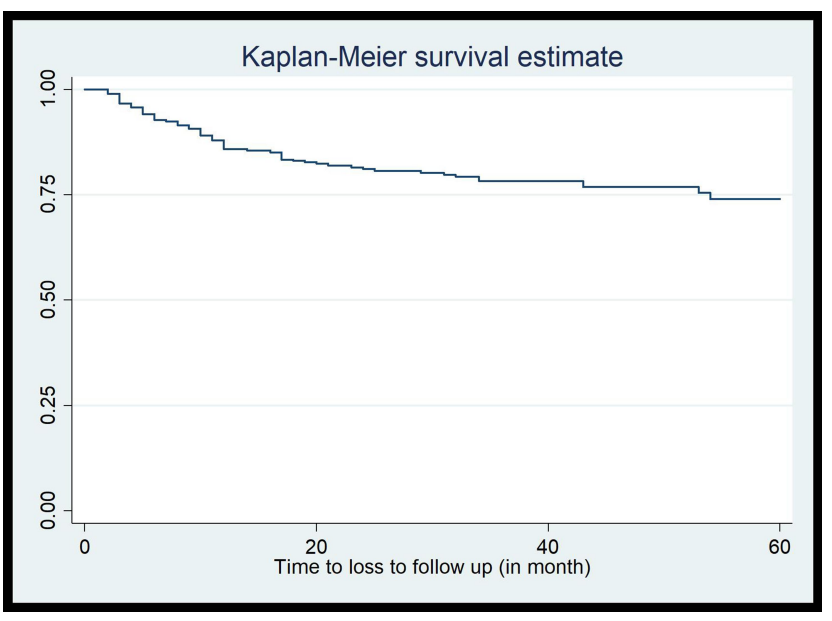

Figure I The Kaplan-Meier estimate of loss to follow-up among patients attending ART at public hospitals in Southern Ethiopia, 2018. characteristics were analyzed. Among the socio demographic variables, residence, distance between home and the health facility and having registered phone numbers had $\mathrm{p}$ value less than 0.05 . Among the clinical characteristics, WHO clinical staging, functional status, most recent CD4 cell count, initiation of INH as a prophylaxis, body mass index and availability of primary caregiver were variables which had $\mathrm{p}$ value less than 0.05 (Table 3 ).

\section{Survival Time Difference Among the Covariates of Variables}

The cumulative survival probability of ART attending patients who had distance less than five kilometers between their home and the hospital at the 10th, 20th, 40th and 60th follow-up month was 0.96 (95\% CI: 0.94, 0.97), 0.94 (95\% CI: 0.92, 0.96), 0.93 (95\% CI: 0.90, 0.95) and 0.93 (95\% CI: $0.90,0.95)$, respectively while it was 0.79 (95\% CI: 0.75, 0.83), 0.66 (95\% CI: 0.61, 0.71), 0.58

Table 3 The Log Rank Estimate of Variables Among ART Attending Patients in Public Hospitals in Southern Ethiopia, 2018

\begin{tabular}{|l|l|l|}
\hline \multirow{2}{*}{ Variables } & \multicolumn{2}{l|}{$\begin{array}{l}\text { Log Rank Estimate of } \\
\text { the Variables }\end{array}$} \\
\cline { 2 - 3 } & $\mathbf{X}^{2}$ & P-value \\
\hline Age (in years) & 2.41 & 0.261 \\
Sex & 1.35 & 0.32 \\
Marital status & 6.17 & 0.16 \\
Educational status & 4.29 & 0.23 \\
Religious status & 1.14 & 0.086 \\
Residence & 66.11 & 0.0001 \\
Occupational status & 8.03 & 0.083 \\
Habit of alcohol intake & 7.10 & 0.103 \\
Habit of cigarette smoking & 5.30 & 0.091 \\
Distance between home and hospital & 163.75 & 0.0001 \\
Registered phone number & 241.84 & 0.0001 \\
WHO clinical staging & 25.90 & 0.0001 \\
Functional status & 52.88 & 0.0001 \\
Most recent CD4 cell count & 8.47 & 0.01 \\
Most recent viral load & 3.76 & 0.137 \\
Opportunistic infections occurrence & 2.49 & 0.337 \\
Disclosure status & 4.91 & 0.092 \\
Presence of active TB & 5.18 & 0.081 \\
Duration under ART(in month) & 7.24 & 0.102 \\
Partner HIV status & 2.83 & 0.692 \\
INH initiation & 124.18 & 0.0001 \\
CPT initiation & 1.24 & 0.871 \\
BMI & 104.87 & 0.0001 \\
ART initiation time & 9.70 & 0.281 \\
Availability of primary care giver & 207.25 & 0.0001 \\
Adherence on ART & 6.21 & 0.431 \\
\hline
\end{tabular}


(95\% CI: $0.53,0.63)$ and 0.50 (95\% CI: $0.44,0.56)$ in similar time periods, respectively, among those ART attending adults who had distance more than five kilometers.

Similarly; the cumulative survival probability among the cohort of adult ART attending patients who have a registered phone number was 0.96 (95\% CI: 0.94, 0.97), 0.91 (95\% CI: $0.89,0.94), 0.90$ (95\% CI: $0.87,0.92)$ and 0.89 (95\% CI: $0.86,0.91)$ at the 10th, 20th, 40th and 60th follow-up months respectively while it was $0.69(95 \% \mathrm{CI}$ : 0.62, 0.75), 0.55 (95\% CI: 0.48, 0.61), 0.37 (95\% CI: 0.30 , $0.45)$ at the $10^{\text {th }}, 20^{\text {th }}$ and $58^{\text {th }}$ month, respectively, among those adults under ART who did not have a registered phone number in their follow-up record (Table 4).

The cumulative survival probability among the cohort of ART attending patients who initiate INH was $0.96(95 \%$ CI: $0.94,0.97)$ at the 10th follow-up month and $0.91(95 \%$

Table 4 The Estimated Survival Time of ART Attending Patients Over Specific Covariate of Variables at Public Hospitals in Southern Ethiopia, 2018

\begin{tabular}{|c|c|c|}
\hline Variables & Category & $\begin{array}{l}\text { Mean Survival } \\
\text { Time }(95 \% \mathrm{Cl})\end{array}$ \\
\hline Residence & $\begin{array}{l}\text { Rural } \\
\text { Urban }\end{array}$ & $\begin{array}{l}42.02(39.41,44.63) \\
53.57(52.18,54.95)\end{array}$ \\
\hline $\begin{array}{l}\text { Distance between home } \\
\text { and hospital }\end{array}$ & $\begin{array}{l}\text { Less than } 5 \mathrm{~km} \\
\text { More than } 5 \\
\mathrm{~km}\end{array}$ & $\begin{array}{l}56.69(55.60,57.79) \\
39.47(37.00,41.94)\end{array}$ \\
\hline Registered phone number & $\begin{array}{l}\text { Yes } \\
\text { No }\end{array}$ & $\begin{array}{l}55.25(54.13,56.37) \\
32.29(29.17,35.39)\end{array}$ \\
\hline WHO clinical staging & $\begin{array}{l}\text { I } \\
\text { II } \\
\text { III \& IV }\end{array}$ & $\begin{array}{l}49.68(46.95,52.39) \\
52.26(50.53,53.99) \\
43.45(40.64,46.26)\end{array}$ \\
\hline Functional status & $\begin{array}{l}\text { Working } \\
\text { Ambulatory } \\
\text { Bed ridden }\end{array}$ & $\begin{array}{l}51.74(50.35,53.14) \\
38.47(34.27,42.67) \\
46.16(40.98,51.35)\end{array}$ \\
\hline $\begin{array}{l}\text { Most recent CD4 cell } \\
\text { count }\end{array}$ & $\begin{array}{l}<200 \\
200-500 \\
>500\end{array}$ & $\begin{array}{l}47.73(45.27,50.18) \\
48.25(46.08,50.42) \\
51.66(49.56,53.76)\end{array}$ \\
\hline INH initiation & $\begin{array}{l}\text { Yes } \\
\text { No }\end{array}$ & $\begin{array}{l}55.08(53.84,56.32) \\
39.67(37.02,42.31)\end{array}$ \\
\hline BMI $\left(\mathrm{kg} / \mathrm{m}^{2}\right)$ & $\begin{array}{l}<18.5 \\
18-24.9 \\
\geq 25\end{array}$ & $\begin{array}{l}32.17(28.70,35.65) \\
52.94(51.56,54.32) \\
47.29(43.26,51.33)\end{array}$ \\
\hline $\begin{array}{l}\text { Availability of primary } \\
\text { care giver }\end{array}$ & $\begin{array}{l}\text { Yes } \\
\text { No }\end{array}$ & $\begin{array}{l}52.8 \mathrm{I}(51.56,54.07) \\
28.66(24.78,32.54)\end{array}$ \\
\hline
\end{tabular}

CI: $0.88,0.93)$ at the 20th follow-up month. In addition, it was 0.91 (95\% CI: $0.88,0.93)$ and 0.86 (95\% CI: 0.81 , 0.89 ) at the 40th and 60th follow-up month, respectively, while it was 0.78 (95\% CI: $0.73,0.82), 0.68$ (95\% CI: $0.62,0.73), 0.57$ (95\% CI: $0.51,0.63)$ and 0.54 (95\% CI: $0.48,0.59)$ at the 10th, 20th, 40th and 60th month, respectively, among those patients who did not initiate INH.

Similarly, the cumulative survival probability among adult ART attending patients who have a primary care giver was 0.92 ( $95 \%$ CI: $0.90,0.94), 0.87$ (95\% CI: 0.85 , $0.89), 0.85$ (95\% CI: $0.82,0.87)$ and 0.85 (95\% CI: 0.82 , 0.87 ) at the 10th, 20th, 40th and 60th follow-up month, respectively, while it was $0.69(0.59,0.76)$, and $0.52(95 \%$ CI: $0.42,0.60)$ at the 10th and 20th follow-up month, respectively, among those ART attending adults who did not have a primary caregiver (Figures 2 and 3).

\section{Predictor of Loss to Follow-Up}

In this study, residence, distance between home and health facility, having a registered phone number on follow-up record, functional status, most recent CD4 cell count, initiation of INH as a prophylaxis and availability of primary care takers were candidates for multivariable cox proportional hazard model in considering $\mathrm{p}$-value less than 0.05 as a cutoff point and WHO clinical staging in considering biological plausibility and previous studies (which had a p-value of 0.09 in bivariate cox proportional hazard model).

ART attending patients who had more than five kilometers distance between their home and the health facility had three times higher risk of loss to follow-up as compared with the counterparts who had less than five kilometers (AHR: 3.71; 95\% CI: 2.32, 5.95). The risk of loss

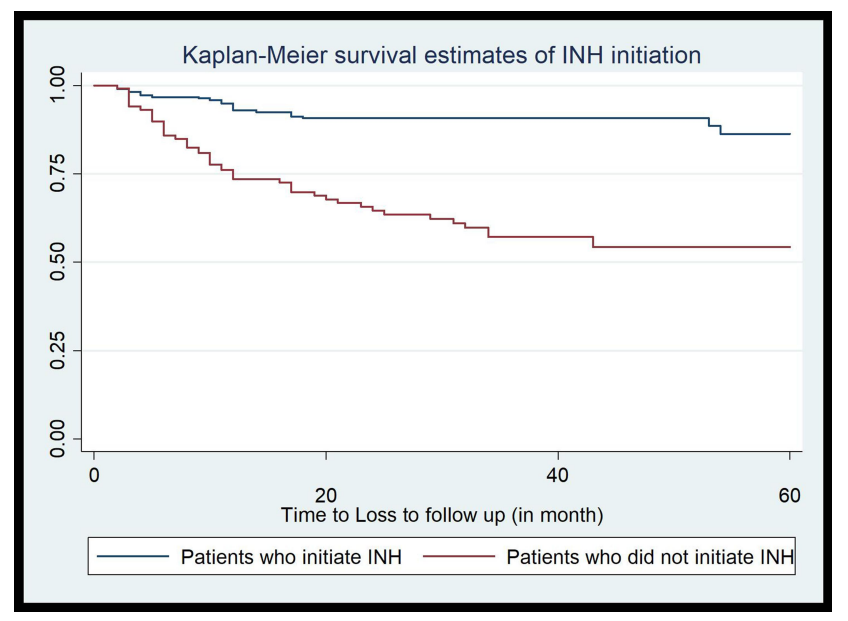

Figure 2 The Kaplan-Meier survival estimate of INH initiation among patients attending ART at public hospitals in Southern Ethiopia, 2018. 


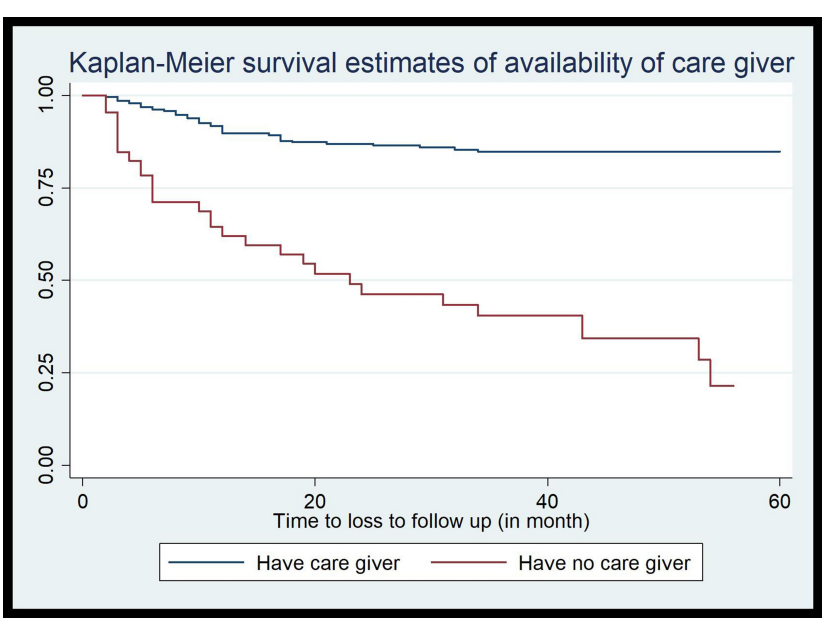

Figure 3 The Kaplan-Meier survival estimate of availability of care giver among patients attending ART at public hospitals in Southern Ethiopia, 2018.

to follow-up from treatment among ART attending patients who did not have registered phone numbers in their follow-up record was two times higher as compared with those who had registered phone numbers (AHR: 2.52; 95\% CI: 1.76, 3.60).
The risk of loss to follow-up among ART attending patients who had BMI less than 18.5 was two times higher as compared with those who had more than 25 and above (AHR: 1.87; 95\% CI: 1.18, 2.97). ART patients who did not initiate INH as a prophylaxis had two times higher risk of loss to follow-up from treatment as compared with the counterparts who initiated INH as a prophylaxis (AHR: 2.15; 95\% CI: 1.50, 3.08). The risk of loss to follow-up among ART attending patients who did not have a primary caregiver was two times higher as compared with the counterparts who have a primary caregiver (AHR: 2.59; 95\% CI: 1.84, 3.66) (Table 5).

\section{Discussion}

This study assesses the survival time and predictors of loss to follow-up from ART services at public hospitals in Ethiopia and finally distance between home and hospital, having registered phone number, INH initiation, body mass index and availability of primary caregivers were statistically significant predictors of loss to follow-up.

Table 5 Predictors of Loss to Follow-Up Among Patients Attending ART at Public Hospitals in Southern Ethiopia, 2018

\begin{tabular}{|c|c|c|c|c|c|}
\hline Variables & Category & Loss to Follow-Up & Censored & CHR(95\% Cl) & $\operatorname{AHR}(95 \% \mathrm{Cl})$ \\
\hline \multirow[t]{2}{*}{ Residence } & Rural & 119 & 208 & $3.12(2.33,4.18)$ & $0.91(0.62,133)$ \\
\hline & Urban & 73 & 520 & I & 1 \\
\hline \multirow[t]{2}{*}{ Distance between home and hospital $(\mathrm{km})$} & Less than 5 & 33 & 507 & I & 1 \\
\hline & More than 5 & 159 & 221 & $7.8 \mid(5.37, \mathrm{I} \mid .36)$ & $3.7 \mid(2.32,5.95)^{*}$ \\
\hline \multirow[t]{2}{*}{ Registered phone number } & Yes & 63 & 623 & I & 1 \\
\hline & No & 129 & 105 & $4.55(5.59,10.22)$ & $2.52(1.76,3.60)^{*}$ \\
\hline \multirow[t]{3}{*}{ WHO clinical stage } & I & 44 & 172 & I & I \\
\hline & II & 66 & 370 & $0.75(0.5 \mathrm{I}, \mathrm{I} .09)$ & $0.64(0.42,1.97)$ \\
\hline & III \&IV & 82 & 186 & $1.67(1.16,2.42)$ & $0.84(0.52,1.35)$ \\
\hline \multirow[t]{3}{*}{ Functional status } & Working & 114 & 612 & I & I \\
\hline & Ambulatory & 58 & 78 & $2.98(2.17,4.09)$ & $1.23(0.79,1.89)$ \\
\hline & Bedridden & 20 & 38 & $2.02(1.26,3.25)$ & $0.97(0.58,1.63)$ \\
\hline \multirow[t]{3}{*}{ Most recent CD4 cell count } & $<200$ & 74 & 251 & $1.22(0.99,1.50)$ & I.58 $(0.83,2.45)$ \\
\hline & $200-500$ & 88 & 289 & $1.19(0.98,1.46)$ & $1.53(0.96,2.44)$ \\
\hline & $>500$ & 30 & 188 & 1 & 1 \\
\hline \multirow[t]{2}{*}{ INH initiation } & Yes & 56 & 528 & I & 1 \\
\hline & No & 136 & 200 & $4.89(3.59,6.69)$ & $2.15(1.50,3.08)^{*}$ \\
\hline \multirow[t]{3}{*}{ BMI $\left(\mathrm{kg} / \mathrm{m}^{2}\right)$} & $<18.5$ & 75 & 96 & $2.13(1.73,2.62)$ & $1.87(1.18,2.97)^{*}$ \\
\hline & $18-24.9$ & 88 & 559 & $0.48(0.39,0.58)$ & $0.96(0.6 \mathrm{I}, \mathrm{I} .52)$ \\
\hline & $\geq 25$ & 29 & 73 & 1 & 1 \\
\hline \multirow[t]{2}{*}{ Availability of primary care giver } & Yes & 108 & 682 & 1 & 1 \\
\hline & No & 84 & 46 & $6.19(4.66,8.25)$ & $2.59(1.84,3.66)^{*}$ \\
\hline
\end{tabular}

Note: *Indicates which have $\mathrm{p}$-value $<0.05$ in multivariable cox proportional hazard model. 
The incidence density rate of loss to follow-up from ART services among ART attending patients was 6.48 (95\% CI: 5.67, 7.29) per 1000 person months. This study finding was less than the study conducted at Pawi General Hospital and South western Uganda which was 11.60 and 26.70 per 100 person months, respectively. ${ }^{4,24}$ In addition, this incidence rate is less than the study conducted at Gonder comprehensive specialized hospital, Mizan-Aman General Hospital and Karamara General Hospital at Jigjiga town, which was $12.26,8.80$ and 26.60 per 1000 person months, respectively. ${ }^{8-10}$ The observed difference between the studies might be due to the time variation between the studies. Recent studies reflect the implementation of different stakeholders strategies. In addition, it might be due to the difference in the socio demographic character of the study participants.

Shorter distance between the home and hospital was associated with the loss to follow-up from ART services. ART attending patients who had more than five kilometers distance between their home and the health facility had a three times higher risk of loss to follow-up as compared with their counterparts who had less than five kilometers (AHR: 3.71; 95\% CI: 2.32, 5.95). This study finding was inconsistent with studies conducted in global northern countries. ${ }^{25}$ In addition, this study finding was similar with the study conducted at Neno district, Malawi, which revealed that those who had long distance have 1.68 times higher risk of loss to follow-up. ${ }^{26}$

Among nationwide studies, this study finding was similar with the study conducted at Benishangul Gumuz Regional State, Western Ethiopia. ${ }^{27}$ This might be due to those individuals who are residing far from the health facility becoming bored with the walks at each schedule. In addition, lack of transportation, individual financial resources for the transport become factors which contribute to the loss to follow-up. ${ }^{28}$

Registration of the phone number of the patient or the caregiver becomes one of the predictors which reduce the risk of loss to follow-up among patients attending ART. In line with the study conducted at Pawi Hospital, North West Ethiopia, ${ }^{29}$ this study finding revealed that the risk of loss to follow-up from treatment among ART attending patients who had not registered a phone number in their follow-up record was two times higher as compared with those who had registered a phone number (AHR: 2.52; 95\% CI: 1.76, 3.60).

This might possibly be due to the successful tracing of patients using their cell phone. Therefore, increasing access to telephone contact became an effective tracing and follow-up strategy for patients under ART. However, this study finding was inconsistent with the study conducted in South Africa, but in these studies there was expected variability having a wide confidence interval (95\% CI: $1.50,47.70) .{ }^{30,31}$

Consistent with the study conducted at North West Ethiopia, Nigeria and rural South Western Uganda, ${ }^{32-34}$ this study indicated that the risk of lost to follow-up among ART attending patients who had BMI less than $18.5 \mathrm{~kg} / \mathrm{m}^{2}$ was two times higher as compared with those who had more than 25 and above (AHR: $1.87 ; 95 \%$ CI: $1.18,2.97)$. This might be due to the treatment failure secondary to the compromised immune system. ${ }^{32}$ In addition, it might be related to the effects of HIV because it highly affects the nutritional status and is related to the occurrence of poor appetite, impaired nutritional absorption, increased basal metabolic rate and occurrence of opportunistic infections. ${ }^{35,36}$ Therefore, such potential health problems can lead the patient to loss from the ART follow-up.

Initiation of Isoniazid preventive therapy had a preventive effect to loss to follow-up. Consistent with the study conducted at Pawi General Hospital, Gonder Comprehensive Specialized Hospital and Mizan-Aman General Hospital, ${ }^{4,8,15}$ ART patients who did not initiate INH as a prophylaxis had two times higher risk of loss to follow-up from treatment as compared with the counterparts who initiate INH as a prophylaxis (AHR: 2.15; $95 \%$ CI: 1.50, 3.08). This study finding was inconsistent with the study conducted in South Africa. ${ }^{37}$

Isoniazid preventive therapy reduces the overall risk of TB in HIV infected individuals by $35 \% .{ }^{38}$ When INH is combined with ART, there is a multiplicative protective effect. $^{39-41}$ In addition, the research support that INH provision should be supported by regular adherence support and monitoring, ideally accompanied by pyridoxine to reduce the risk of asymptomatic peripheral neuropathy. Therefore, INH initiation will prevent loss to follow-up in controlling the occurrence of TB among ART attending adults.

The risk of loss to follow-up among ART attending patients who did not have a primary care giver was two times higher as compared with the counterparts who have a primary care giver (AHR: 2.59; 95\% CI: 1.84, 3.66). This study finding was similar with the study conducted in South Africa. ${ }^{42}$ This might be due to family support, which means families may have greater emotional support 
that offered by family greater than from clinic staff in providing opportunity for others to provide reassurance to the individual that it clinic attendance is not yet enough.

\section{Limitations of the Study}

As a limitation, this study did not consider some essential predictors like liver, and renal function tests, since it was conducted using secondary data that have missing records. In addition to the above, it might lead to underestimating the incidence rate of loss to follow-up owing to record problems.

\section{Conclusion}

The incidence density rate in Southern Ethiopia is lower as compared with other studies. The time until loss to followup from treatment was high in the first 20 months of the initiation of the ART follow-up and it declines after 20 months; having longer distance between home and hospital, not having registered a phone number of the patient or the relatives, unable to initiate $\mathrm{INH}$, lower body mass index and did not have a primary care giver were the independent predictors of loss to follow-up from ART services. Furthermore, phone number registration and initiating INH should be encouraged through the hospitals and patients should feed balanced diet to have adequate body mass index.

\section{Abbreviations}

AHR, adjusted hazard ratio; AIDS, acquired immune deficiency syndrome; ART, antiretroviral therapy; CHR, crude hazard ratio; CI, confidence interval; HIV, human immunodeficiency virus; IDR, incidence density ratio; OIs, opportunistic infections; TB, tuberculosis.

\section{Data Sharing Statement}

The data sets generated and/or analyzed are available with a reasonable request through the corresponding author.

\section{Acknowledgments}

We would like to thank the administrator of each hospital for their effort and permission to conduct the study.

\section{Author Contributions}

All authors made a significant contribution to the work reported, whether that is in the conception, study design, execution, acquisition of data, analysis and interpretation, or in all these areas; took part in drafting, revising or critically reviewing the article; gave final approval of the version to be published; have agreed on the journal to which the article has been submitted; and agree to be accountable for all aspects of the work.

\section{Funding}

There is no funding to report.

\section{Disclosure}

The authors report no conflicts of interest for this work.

\section{References}

1. The Ethiopian public health institute. HIV Related Estimates and Projections in Ethiopia for the Year 2019; 2020.

2. May MT, Gompels M, Delpech V, et al. Impact on life expectancy of HIV-1 positive individuals of CD4R cell count and viral load response to antiretroviral therapy. AIDS. 2014;28(8):1193-1202. doi:10.1097/QAD.0000000000000243

3. WHO. US/HIV AIDS Report; 2015.

4. Assemie MA, Muchie KF, Ayele TA. Incidence and predictors of loss to follow up among HIV-infected adults at Pawi General Hospital, northwest Ethiopia: competing risk regression model. BMC Res Notes. 2018;11:287. doi:10.1186/s13104-018-3407-5

5. WHO. HIV/AIDS Fact Sheets; 2019.

6. UNAIDS. Global HIV \& AIDS Statistics - 2019 Fact Sheet; 2019.

7. Bekolo CE, Webster J, Batenganya M, Sume GE, Kollo B. Trends in mortality and loss to follow-up in HIV care at the Nkongsamba Regional hospital, Cameroon. BMC Res Notes. 2013;6(1):512. doi:10.1186/1756-0500-6-512

8. Berheto TM, Haile DB, Mohammed S. Predictors of loss to followup in patients living with HIV/AIDS after initiation of antiretroviral therapy. North Am J Med Sci. 2014;6:453-459. doi:10.4103/19472714.141636

9. Mekonnen N, Abdulkadir M, Shumetie E, Gebreegziabher AB, Kindie MY. Incidence and predictors of loss to follow-up among HIV infected adults after initiation of first line anti-retroviral therapy at University of Gondar comprehensive specialized Hospital Northwest Ethiopia, 2018: retrospective follow up study. BMC Res Notes. 2019;12:111. doi:10.1186/s13104-019-4154-y

10. Seifu W, Ali W, Meresa B. Predictors of loss to follow up among adult clients attending antiretroviral treatment at Karamara general hospital, Jigjiga town, Eastern Ethiopia, 2015: a retrospective cohort study. BMC Infect Dis. 2018;2018(1):280. doi:10.1186/s12879-018-3188-4

11. Rosen S, Fox MP, Gill CJ. Patient retention in antiretroviral therapy programs in sub-Saharan Africa: a systematic review. PLoS Med. 2007;4(10):e298. doi:10.1371/journal.pmed.0040298

12. Leroy V, Malateste K, Rabie H, et al. Outcomes of antiretroviral therapy in children in Asia and Africa: a comparative analysis of the IeDEA pediatric multiregional collaboration. J Acquir Immune Defic Syndr. 2013;62(2):208. doi:10.1097/QAI.0b013e31827b70bf

13. Melaku Z, Lulseged S, Wang C, et al. Outcomes among HIV-infected children initiating HIV care and antiretroviral treatment in Ethiopia. Trop Med Int Health. 2017;22(4):474-484. doi:10.1111/tmi.12834

14. Li X, Margolick JB, Conover CS, et al. Interruption and Discontinuation of Highly Active Antiretroviral Therapy in the Multicenter AIDS Cohort Study. J Acquir Immune Defic Syndr. 2005;38(3):320-328.

15. Teshale AB, Tsegaye AT, Wolde HF. Incidence and predictors of loss to follow up among adult HIV patients on antiretroviral therapy in University of Gondar Comprehensive Specialized Hospital: a competing risk regression modeling. PLoS One. 2020;15(1):e0227473. doi:10.1371/journal.pone. 0227473 
16. Estil J, Tweya H, Egger M, et al. Tracing of patients lost to follow-up and HIV transmission: mathematical modelling study based on two large ART programmes in Malawi. J Acquir Immune Defic Syndr. 2014;65(5):e179. doi:10.1097/QAI.0000000000000075

17. Taiwo B. Understanding transmitted HIV resistance through the experience in the USA. Int $J$ Infect Dis. 2009;13(5):552-559. doi:10.1016/j.ijid.2008.10.008

18. Meloni TT, Chang CA, Eisen G, et al. Long-Term Outcomes on Antiretroviral Therapy in a Large Scale-Up Program in Nigeria. PLoS One. 2016;11(10):e0164030. doi:10.1371/journal.pone.0164030

19. Stephen BA, Michael K, Bosco B, Samson O, Winnie M. Predictors of dropout from care among HIV-infected patients initiating antiretroviral therapy at a public sector HIV treatment clinic in sub-Saharan Africa. BMC Infect Dis. 2016;16:43.

20. Abebe M, Sileshi G, Tolosa E, et al. Predictors of loss to follow-up in antiretroviral treatment for adult patients in the Oromia region, Ethiopia. HIV/AIDS Res Palliat Care. 2016;8:83-92.

21. Wubshet M, Berhane Y, Worku A, Kebede Y, Diro E. High Loss to Followup and Early Mortality Create Substantial Reduction in Patient Retention at Antiretroviral Treatment Program in North-West Ethiopia. Isrn Aids. 2012;2012:1-9. doi:10.5402/2012/721720

22. Ayele W, Mulugeta A, Desta A, Rabito FA. Treatment outcomes and their determinants in HIV patients on Anti-retroviral Treatment Program in selected health facilities of Kembata and Hadiya zones, Southern Nations, Nationalities and Peoples Region, Ethiopia. BMC Public Health. 2015;15(1):1-13. doi:10.1186/s12889-015-2176-5

23. Tiruneh YM, Gala'rraga O, Genberg B, Wilson IB. Retention in care among HIV-infected adults in Ethiopia, 2005-2011: a mixed-methods study. PLoS One. 2016;11(6):2005-2011. doi:10.1371/journal.pone.0156 619

24. Nuwagira E, Rhoda WM, Amir A. Predictors of Loss to Follow up among HIV Infected Patients Initiated on Second Line ART in Southwestern Uganda. HIV. 2018;3:2.

25. Kelly C, Hulme C, Farragher T, Clarke G. Are differences in travel time or distance to healthcare for adults in global north countries associated with an impact on health outcomes? A systematic review. BMJ Open. 2016;6(11):e013059. doi:10.1136/bmjopen-2016-013059

26. Bilinski A, Birru E, Peckarsky M, et al. Distance to care, enrollment and loss to follow-up of HIV patients during decentralization of antiretroviral therapy in Neno District, Malawi: a retrospective cohort study. PLoS One. 2017;12(10):e0185699. doi:10.1371/journal.pone. 0185699

27. Muluwas A, Girma T. Predictors of loss to follow up in patients living with HIV/AIDS after initiation of antiretroviral therapy in Benshangul Gumuz Regional State, Western Ethiopia. Int Invent Sci J. 2019;3:11.

28. Geng EH, Bangsberg DR, Musinguzi N, et al. Understanding reasons for and outcomes of patients lost to follow-up in antiretroviral therapy programs in africa through a sampling-based approach. J Acquir Immune Defic Syndr. 2010;53(3):405-411. doi:10.1097/QAI.0b013e $3181 \mathrm{~b} 843 \mathrm{f0}$

29. Assemie MA, Leshargie CT, Petrucka P. Outcomes and factors affecting mortality and successful tracing among patients lost to follow-up from antiretroviral therapy in Pawi Hospital, Northwest Ethiopia. Trop Med Health. 2019;47(1):52. doi:10.1186/s41182-019-0181-6
30. Zürcher K, Mooser A, Anderegg N, et al. Outcomes of HIV-10. Positive patients lost to follow-up in Africantreatment programmes. Trop Med Int Health. 2017;22(4):375-387. doi:10.1111/tmi.12843

31. Maskew M, MacPhail P, Menezez C, Rubel D. Lost to follow upcontributing factors and challenges in south African patients on antiretroviral therapy. South African Med j. 2007;97(9):853-857.

32. Agezew T, Abilo T, Derseh L, Yimer M. Incidence and Predictors of First Line Anti-Retroviral Therapy Failure among Adults Receiving HIV Care in North West Ethiopia: a Hospital-Based Follow-Up Study. J Infect Dis Epidemiol. 2019;5:072.

33. Musa BM, Coker M, Bussell S, et al. Long-term outcomes of antiretroviral therapy in an adult HIV program: a 10-year retrospective cohort study in Kano, Nigeria. Ann Saudi Med. 2015;35(4):303-311. doi:10.5144/0256-4947.2015.303

34. Kazooba P, Mayanja BN, Levin J, Masiira B, Kaleebu P. Virological failure on first-line antiretroviral therapy; associated factors and a pragmatic approach for switching to second line therapy-evidence from a prospective cohort study in rural South-Western Uganda, 2004-2011. Pan Afric Med J. 2018;29:191.

35. Marshall CS, Curtis AJ, Spelman T, et al. Impact of HIV-associated conditions on mortality in people commencing anti-retroviral therapy in resource limited settings. PLoS One. 2013;8(7):e68445. doi:10. 1371/journal.pone.0068445

36. Süttmann U, Ockenga J, Selberg O, Hoogestraat L, Deicher H, Müller MJ. Incidence and prognostic value of malnutrition and wasting in human immunodeficiency virus-infected outpatients. J Acquir Immune Defic Syndr. 1995;8:239-246. doi:10.1097/00042560-19950 3010-00004

37. Beneri CA, Zeldow B, Nachman S, et al. Loss to follow-up among infants in a study of isoniazid prophylaxis (P1041) in South Africa. Int J Tuberc Lung Dis. 2013;17(1):32-38. doi:10.5588/ijtld.12.0282

38. Ayele HT, Mourik MS, Debray TP, Bonten MJ. Isoniazid prophylactic therapy for the prevention of tuberculosis in HIV infected adults: a systematic review and meta-analysis of randomized trials. PLoS One. 2015;10:e0142290. doi:10.1371/journal.pone.0142290

39. Lawn SD, Wood R, Cock KMD, Kranzer K, Lewis JJ, Churchyard GJ. Antiretrovirals and isoniazid preventive therapy in the prevention of HIV associated tuberculosis in settings with limited health-care resources. Lancet Infect Dis. 2010;10:489-498. doi:10.1016/S14733099(10)70078-5

40. Taraz S, Terefa BA, Samba N, et al. 6-month versus 36-month isoniazid preventive treatment for tuberculosis in adults with HIV infection in Botswana: a randomised, double-blind, placebo-controlled trial. Lancet Infect Dis. 2011;377(9777):1588-1598.

41. Durovni B, Saraceni V, Moulton LH, et al. Effect of improved tuberculosis screening and isoniazid preventive therapy on incidence of tuberculosis and death in patients with HIV in clinics in Rio de Janeiro, Brazil: a stepped wedge, cluster-randomised trial. Lancet Infect Dis. 2013;13(10):852-858. doi:10.1016/S1473-3099(13)701 87-7

42. Rachel A, Anthony PM, Sheela VS. Predictors of loss to follow-up among patients on ART at a rural hospital in KwaZulu-Natal, South Africa. PLoS One. 2017;12(5):e0177168. doi:10.1371/journal.pone. 0177168
HIV/AIDS - Research and Palliative Care

\section{Publish your work in this journal}

HIV/AIDS - Research and Palliative Care is an international, peerreviewed open-access journal focusing on advances in research in HIV, its clinical progression and management options including antiviral treatment, palliative care and public healthcare policies to control viral spread. The manuscript management system is completely online and includes a very quick and fair peer-review system, which is all easy to use. Visit http://www.dovepress.com/testimonials.php to read real quotes from published authors. 